\title{
Assessment of models predicting anthropogenic interventions and climate variability on surface runoff of the Lower Zab River
}

\author{
R. Mohammed ${ }^{1} \cdot$ M. Scholz ${ }^{1,2} \cdot$ M. A. Nanekely ${ }^{1} \cdot$ Y. Mokhtari $^{1}$
}

Published online: 29 December 2016

(C) The Author(s) 2016. This article is published with open access at Springerlink.com

\begin{abstract}
Multi-regression, hydrologic sensitivity and hydrologic model simulations were applied to quantify the climate change and anthropogenic intervention impacts on the Lower Zab River basin (LZRB). The Pettitt, precipitation-runoff double cumulative curve (PR-DCC) and Mann-Kendall methods were used for the change points and significant trend analyses in the annual streamflow. The long-term runoff series from 1979 to 2013 was first divided into two main periods: a baseline (1979-1997) and an anthropogenic intervention period (1998-2013). The findings show that the mean annual streamflow changes were consistent using the three methods. In addition, climate variability was the main driver, which led to streamflow reduction with contributions of 66-97\% during 2003-2013, whereas anthropogenic interventions caused reductions of $4-34 \%$. Moreover, to enhance the multimodel combination concept and explore the simple average method (SAM), Hydrologiska Byrans Vattenbalansavdelning (HBV), Génie Rural a Daily 4 parameters (GR4J) and Medbasin models have been successfully applied.
\end{abstract}

Keywords Climate change $\cdot$ Human-induced impacts . Hydrologic sensitivity analysis - Multi-model combination technique $\cdot$ Multi-regression $\cdot$ Runoff simulation

M. Scholz

miklas.scholz@tvrl.lth.se

1 Civil Engineering Research Group, School of ComputingScience and Engineering, University of Salford, Newton Building, Peel Park Campus, Salford, Greater Manchester M5 4WT, UK

2 Division of Water Resources Engineering, Faculty of Engineering, Lund University, P.O. Box 118, 22100 Lund, Sweden

\section{Introduction}

\subsection{Background}

Alterations in streamflow as a result of climate change linked with the anthropogenic interventions have long been the main focus of hydrological studies (Guo et al. 2014; Jiang et al. 2011). Generally speaking, the climate change is considered as the focal factor changing precipitation patterns. However, anthropogenic interventions have affected the water resources temporally and spatially. The impacts of these two factors on streamflow are sensitive, particularly in semi-arid and arid geographical regions, which resulted in serious environmental degradations and water crisis (Zhang et al. 2001; Miao et al. 2011; Chang et al. 2015). Hence, assessing factors that impact on alterations of river flow have drawn considerable concerns.

A growing number of studies focus on evaluating the ratio of climate change and anthropogenic interventions on basin streamflow (Jiang et al. 2011; Wang et al. 2012; Ye et al. 2013; Guo et al. 2014; Jiang et al. 2015; Mao et al. 2015; Cheng et al. 2016; Huang et al. 2016). Such impacts vary based on geographical region; accordingly, they are commonly explored at a regional scale such as on subbasin or basin scale. For instance, Ma et al. (2008) predicted that climate variability accounted for over $64 \%$ of the reduction in average yearly streamflow, mainly as a result of precipitation decline.

The impacts of anthropogenic interventions and climate variability can be quantified through adopting the following steps: firstly, determining the change points in climatic data since it would influences the results in assessing other factors (Cheng et al. 2016). Specifying such points can be achieved by using statistical methods such as the MannKendall trend analysis (M-K) (Chen and Xu 2005; Kahya 
and Kalayci 2004; Mao et al. 2015), the Pettitt's analysis or the precipitation-runoff double cumulative curve technique (Jiang et al. 2011; Guo et al. 2014; Vaheddoost and Aksoy 2016). Accordingly, the hydrological years before the alteration are considered as a baseline, then the impact of the climate change period can be isolated from the baseline period. The second step is to apply methods that determine the climate change effects. Hence, the reminder of the effects is then attributed to other factors such as land use land cover, direct withdrawal of water from surface or subsurface flow for municipal, industrial production and irrigation purposes, and other different purposes which are considered as anthropogenic interventions (Zhao et al. 2010).

In order to identify the impacts of climate variability and anthropogenic interventions on streamflow, a large number of methodologies have been proposed (Li et al. 2007; Ma et al. 2008; Miao et al. 2011; Wang et al. 2012; Guo et al., 2014; Chang et al. 2015; Cheng et al. 2016). The rainfallrunoff model simulation is usually considered as the most widely spread method (Futter et al. 2015; Jiang et al. 2011; Jones et al. 2004; Zhang et al. 2001). For example, Li et al. (2007) suggested a framework to predict the mean runoff sensitivity on precipitation and potential evapotranspiration. The technique was then employed to evaluate the anthropogenic interventions and climate change impacts on streamflow (Li et al. 2007; Zhang et al. 2001). However, some modernistic endeavours have been developed to address this environmental issue using linear regression analysis (Li et al. 2007; Zhao et al. 2010).

A rainfall-runoff simulation is an estimated explanation of the problematical hydrologic phenomena that happen in the environment. Such model is a potentially powerful tool to solve practical hydrological challenges. In addition, the model is considered as an effective method for understanding the complex water cycle processes.

Rainfall-runoff models have advanced from empirical models to conceptual ones and thus to distributed models. Hydrological estimation accuracy has improved over time. However, there are often diverse modelling uncertainties such as model parameters as well as data and model structural errors (Jiang et al. 2014). Uncertainties in hydrological modelling have been studied previously (Ajami et al. 2007; Duan et al. 2007; Vallam et al. 2014; Zheng et al. 2014). Zheng et al. (2014) demonstrated that hydrological model parameter uncertainties have great impacts on the model simulation results. The uncertainties in model simulation during wet periods are relatively higher than those during dry periods.

Numerous rainfall-runoff models are available, and each model describes the processes of hydrological events. There is currently no single model that can describe the principles of basin rainfall-runoff covering all conditions.
Therefore, multi-model approaches depend on the results of several models, and can improve the accuracy of hydrological prediction through a reduction of the model structure uncertainty.

This study focuses on applying a simple multi-model approach to perform streamflow simulations and uncertainty analyses. As a representative case study, the Lower Zab River basin (LZRB), which is considered one of the important basins in the northern part of Iraq, contributing to the flow rate of the Tigris River (Fig. 1). In addition, there are four other basin regions, which are the Diyala, Khabur, Upper Zab (Greater Zab) and Uzem. Over the past few years, the northern area of Iraq has been severely impacted by climatic variations, water shortage, drought phenomena and some casual flood events. Droughts have negatively impacted the wide range of areas in the studied region. However, floods only sometimes happened over the winter season due to of heavy rainfall and the lack of dams and artificial drainage networks, which result in socioeconomic damages in the region (Sen et al. 2012; Al-Ansari 2013; Saeedrashed and Guven 2013; Al-Ansari et al. 2014; Devi et al. 2015). To date, the LZRB runoff has significantly declined during recent water years as reported by various studies (Chen and $\mathrm{Xu}$ 2005; Saeedrashed and Guven 2013). Anthropogenic interventions such as dam and reservoir constructions, irrigation and drainage systems, land use and land cover alterations in addition to climate change have been considered to be the main reasons for the decline in the LZRB runoff (Bozkurt and Sen 2012; Bozkurt et al. 2015). An evaluation of the relative contributions of anthropogenic interventions and climate change to streamflow alteration in the LZRB has not been performed, yet.

\subsection{Rationale, aim, objectives and significance}

Land use and land cover have been demonstrated universally to be the main factors impacting on river basin flow (Li et al. 2007; Huo et al. 2008; Miao et al. 2011; Wang et al. 2012; Guo et al. 2014; Chang et al. 2015). However, detailed assessments on the long-term change in streamflow to the LZRB and the distinct contribution of anthropogenic interventions and climate change have not been reported upon. The main target of the current study is to answer the following question: To what extent do anthropogenic interventions and climate change impact on the alteration of runoff within the LZRB? The answer depends on three of the most commonly accepted runoff simulation methods applied in this study, which are the Medbasin, GR4J and HBV models. Accordingly, the objectives of the study are as follows:

- To analysis the basin streamflow temporal variations; 


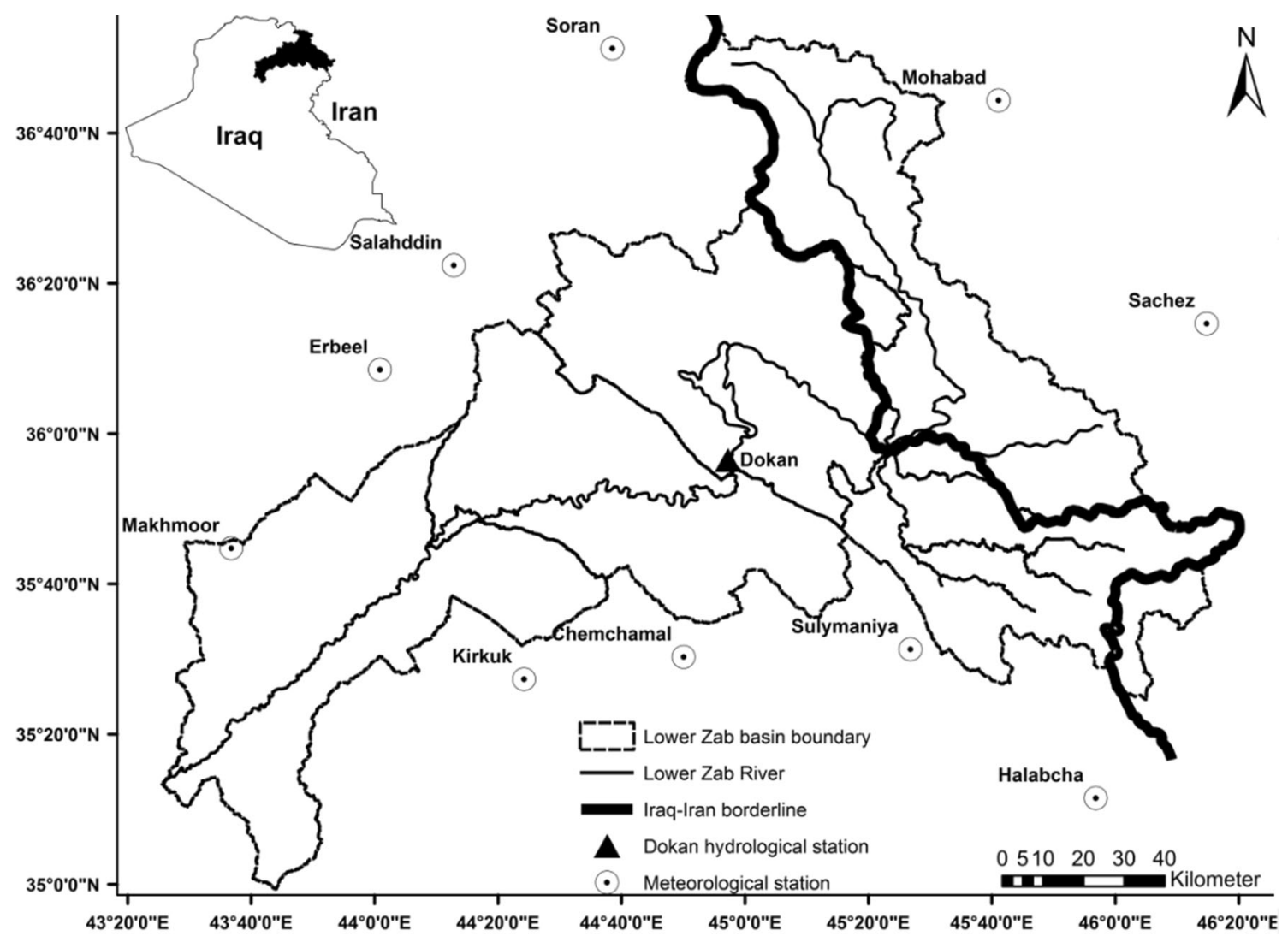

Fig. 1 Locations of the selected meteorological stations

- To detect critical change points and trends of annual basin streamflow;

- To understand the main driving factors for the recorded streamflow alterations;

- To assess the relative contributions of climate change and anthropogenic interventions such as land use change, reservoir construction and in-channel damming on basin streamflow; and

- To evaluate how the accuracy of multi-model simulation is influenced by the seasonal variations of hydrological processes, and the accuracy level of individual member models.

The models applied (Sect. 2.5) have different structural assumptions and data requirements. They were selected to ensure that they cover a wide range of possibilities to maximise the benefits obtained from combining their outputs. The results of this study can be used for regional water resources evaluation and utilisation as well as managing benchmarks by shading light on the abrupt changes and trends of historical hydrological data for the whole studied geographical region and similar ones elsewhere. In the next section available data and methods are introduced, followed by various runoff simulation approach descriptions. The obtained results are then discussed, and key conclusions are drawn.

\section{Available data and methods}

\subsection{Representative case study}

The Lower Zab River (also known as Little Zab River and Lesser Zab River) is one of the main tributaries of the Tigris River in the Erbil governorate in the north-east of Iraq. The basin is divided between Iraq and Iran with a total area of $19,846 \mathrm{~km}^{2}$. About $75 \%$ of this area is located in Iraq. The entire length of $370 \mathrm{~km}$ covers areas between the south-east and south-west of Iraq on one side and northwestern Iran and northern Iraq on the other side before joining the Tigris near Fatha city, which is located about $220 \mathrm{~km}$ north of Baghdad (Tsakiris et al. 2007). The river and its tributaries are located between latitudes $36^{\circ} 50^{\prime} \mathrm{N}$ and $35^{\circ} 20^{\prime} \mathrm{N}$, and longitudes $43^{\circ} 25^{\prime} \mathrm{E}$ and $45^{\circ} 50^{\prime} \mathrm{E}$ (Saeedrashed and Guven 2013; Seibert and Vis 2012) as shown in Fig. 1. The considered river basin is situated in a semiarid to arid climate zone. The annual precipitation within 
the basin is approximately $720 \mathrm{~mm}$. The current study is restricted to the basin upper part with an overall drainage area of $14,924 \mathrm{~km}^{2}$.

This research examines the daily flow rate for the hydrological years between 1979 and 2013 at Dokan station, which is considered as a key hydrometric gauging station (latitude $35^{\circ} 53^{\prime} 00^{\prime \prime} \mathrm{N}$ and longitude $44^{\circ} 58^{\prime} 00^{\prime \prime} \mathrm{E}$ ). The considered area has suffered from drought in recent years. The water year 2008 was the driest. The Lower Zab River has relatively high flows during summer due to releases of water from the Dokan reservoir to supply the agricultural industry and urban users.

\subsection{Data collection and analysis}

Daily meteorological data from seven stations with elevations ranging from 319 to $1536 \mathrm{~m}$ (Table 1) were available for the period between 1979/1980 and 2012/2013. The data were assigned to the watershed and subsequently adjusted to the average elevation of the watershed. The collected information comprises daily streamflow data accessible for Dokan station (latitude $35^{\circ} 53^{\prime} 00^{\prime \prime} \mathrm{N}$ and longitude $44^{\circ} 58^{\prime} 00^{\prime \prime} \mathrm{E}$ ) for a duration of 35 years. The representative sub-basin area for this part of the study is $14,924 \mathrm{~km}^{2}$. The data were obtained from the Ministry of Agriculture and Water Resources in the Kurdistan region of Iraq (personal communication).

ArcGIS 10.3 has been used for meteorological and hydrological station location projections, Thiessen network computations and river basin delineation. Table 1 reveals the latitude, longitude and elevation of the meteorological stations covering the studied basin. Additionally, statistical analyses for the daily meteorological and hydrological data, including trend analysis, monthly and annual average values, corrections and gap filling, were performed using the Statistical Program for Social Sciences (SPSS) 20. The Pettitt test has been performed using XLSTAT, which is an add-in for Excel. Table 2 reveals Mann-Kendall test findings for the key meteorological variables. The estimation of potential evapotranspiration PET $(\mathrm{mm})$ was accomplished based on the Food and Agriculture Organization Penman-Monteith standard method (Allen et al. 1998), which was calculated depending on the reference evapotranspiration $\mathrm{ET}_{\mathrm{o}}(\mathrm{mm})$ calculator version 3.2 (FAO 2012).

In order to achieve an accurate estimation of the spatial distribution of rainfall, it is necessary to use interpolation methods. The weighing mean method is often considered as the most important one for engineering praxis. This method assigns weights at each gauging station in proportion to the basin area, which is closest to that station. To set up the method, the following steps have been accomplished using ArcGIS. The creation of a shapefile of the
Table 1 Overview of basin station locations

\begin{tabular}{llll}
\hline Station name & Longitude $\left(^{\circ}\right)$ & Latitude $\left({ }^{\circ}\right)$ & Elevation $(\mathrm{m})$ \\
\hline Kirkuk & 44.40 & 35.47 & 319 \\
Chem-Chamal & 44.83 & 35.52 & 701 \\
Sulymanya & 45.45 & 35.53 & 885 \\
Halabcha & 45.94 & 35.44 & 651 \\
Makhmoor & 43.60 & 35.75 & 306 \\
Salahddin & 44.20 & 36.38 & 1088 \\
Erbeel & 44.00 & 36.15 & 1088 \\
Soran & 44.63 & 36.87 & 1132 \\
Mahabad & 45.70 & 36.75 & 1356 \\
Sachez & 46.26 & 36.25 & 1536 \\
\hline
\end{tabular}

named watershed polygons as a function of the land cover image has been achieved by downloading the relevant information from the Global Land Cover Facility.

This step was followed by the creation of two shapefiles. The first one is the basin border polygon, while the second one is the point shapefile that represents meteorological stations. Each point representation is linked to a value of the long-term precipitation. A Thiessen network was created to estimate the area of each station polygon $\left(a_{i}\right)$. This has been achieved depending on the following: (a) connecting the adjacent stations with lines; (b) constructing perpendicular bisectors of each line, and (c) extending the bisectors and applying them to form polygons around each station. Table 3 lists the station addresses with corresponding average precipitation and potential evapotranspiration and the sub-area sizes.

Rainfall and potential evapotranspiration values for each gauging station were multiplied by the area of each polygon $a_{i}\left(\mathrm{~km}^{2}\right)$. The next step required the computation of the average values of the average precipitation $P_{m}(\mathrm{~mm})$ and average potential evapotranspiration $P E T_{m}(\mathrm{~mm})$ by

Table 2 Station addresses with corresponding average precipitations and the sub-area sizes

\begin{tabular}{llll}
\hline Station ID & Sub-area $\left(\mathrm{km}^{2}\right)$ & $\mathrm{Av}^{\mathrm{a}} \mathrm{P}^{\mathrm{b}}(\mathrm{mm})$ & $\mathrm{Av}^{\mathrm{a}} \mathrm{PET}^{\mathrm{c}}(\mathrm{mm})$ \\
\hline Sulymaniya & 4479.57 & 772 & 1989 \\
Mohabad & 2593.31 & 886 & 920 \\
Soran & 1463.30 & 813 & 1433 \\
Chem-Chamal & 2827.46 & 738 & 2075 \\
Sachez & 1182.79 & 462 & 1550 \\
Salahddin & 1641.07 & 652 & 2058 \\
Halabcha & 735.60 & 585 & 980 \\
\hline
\end{tabular}

\footnotetext{
${ }^{a}$ Average

b Precipitation

c Potential evapotranspiration
} 
Table 3 Long-term average monthly to long-term annual precipitation ratios

\begin{tabular}{lllllll}
\hline Station name & \multicolumn{7}{l}{ Percentage of long-term annual precipitation ratio } \\
\cline { 2 - 6 } & October & November & December & January & February & March \\
\hline Kirkuk & 4.94 & 13.41 & 16.89 & 17.83 & 16.96 & 16.56 \\
Chem-Chamal & 5.17 & 13.14 & 16.53 & 17.48 & 16.91 & 16.21 \\
Sulymanya & 4.53 & 12.16 & 16.42 & 18.63 & 17.42 & 16.83 \\
Halabcha & 3.87 & 10.92 & 16.33 & 18.01 & 19.01 & 17.55 \\
Makhmoor & 6.78 & 13.11 & 15.66 & 17.09 & 15.56 & 17.11 \\
Salahddin & 4.09 & 12.18 & 15.82 & 18.10 & 18.14 & 16.92 \\
Erbeel & 5.87 & 12.93 & 15.91 & 17.27 & 16.53 & 16.48 \\
Soran & 5.04 & 12.19 & 13.78 & 13.91 & 15.62 & 16.66 \\
Mohabad & 5.88 & 11.91 & 14.26 & 15.76 & 16.19 & 16.65 \\
Sachez & 4.17 & 11.27 & 15.27 & 16.80 & 17.04 & 17.94 \\
\hline
\end{tabular}

Station name Percentage of long-term annual precipitation ratio

\begin{tabular}{lrrrrrr} 
& April & May & June & July & August & September \\
\hline Kirkuk & 9.06 & 4.09 & 0.17 & 0.00 & 0.00 & 0.10 \\
Chem-Chamal & 9.92 & 4.38 & 0.13 & 0.00 & 0.00 & 0.12 \\
Sulymanya & 9.75 & 4.05 & 0.10 & 0.00 & 0.00 & 0.11 \\
Halabcha & 10.64 & 3.39 & 0.12 & 0.02 & 0.00 & 0.14 \\
Makhmoor & 9.53 & 4.73 & 0.17 & 0.00 & 0.00 & 0.25 \\
Salahddin & 10.82 & 3.70 & 0.10 & 0.00 & 0.00 & 0.13 \\
Erbeel & 10.26 & 4.31 & 0.18 & 0.00 & 0.00 & 0.26 \\
Soran & 14.74 & 6.91 & 0.73 & 0.08 & 0.11 & 0.23 \\
Mohabad & 12.26 & 6.32 & 0.41 & 0.07 & 0.05 & 0.25 \\
Sachez & 11.20 & 5.78 & 0.25 & 0.05 & 0.01 & 0.22 \\
\hline
\end{tabular}

summing up all values obtained from the previous step and dividing the corresponding number by the total basin area according to Eq. (1). Stations are distributed both inside and outside basin polygons (Fig. 1). Only one average value $M$ per station has been provided to keep the procedure simple.

$M_{m}=\frac{\sum_{i=1}^{n} a_{i} \times M_{i}}{\sum_{i=1}^{n} a_{i}}$

where $M_{m}$ is the average value of the basin precipitation $P(\mathrm{~mm})$ or PET $(\mathrm{mm}), a_{i}\left(\mathrm{~km}^{2}\right)$ is the meteorological station area, and $M_{i}(\mathrm{~mm})$ is the average value of the station polygon $M$.

Furthermore, the ratios of the long-term average monthly precipitation to the long-term average annual precipitation for the studied hydrologic year period, which started from October, are listed in Table 3. Data analysis outcomes show that the accumulated precipitation over the wet months, which are from October to May, accounts to nearly $99.5 \%$ of the entire yearly precipitation. However, the aggregated precipitation during the dry months, which are from June to September, contributes to just about $0.5 \%$ of the total precipitation.

\subsection{Potential evapotranspiration estimation}

The FAO Penman-Monteith method is primarily applied to estimate $E T_{o}$ as indicated in Eq. (2).

$E T_{o}=\frac{0.408 \times\left(R_{n}-G\right)+\gamma \times \frac{900}{T_{m}+273} u_{2} \times\left(e_{s}-e_{a}\right)}{\Delta+\gamma \times\left(1+0.34 \times u_{2}\right)}$

where $E T_{o}(\mathrm{~mm} /$ day) is the reference evapotranspiration, $R_{n}\left(\mathrm{MJ} / \mathrm{m}^{2} /\right.$ day $)$ is the net radiation at the crop surface, $G\left(\mathrm{MJ} / \mathrm{m}^{2} \times\right.$ day $)$ is the soil heat flux density, $\gamma\left(\mathrm{kPa} /{ }^{\circ} \mathrm{C}\right)$ is the psychrometric constant, $T_{m}\left({ }^{\circ} \mathrm{C}\right)$ is the mean air temperature, $u_{2}(\mathrm{~m} / \mathrm{s})$ is the wind speed at $2-\mathrm{m}$ elevation, $e_{s}$ $(\mathrm{kPa})$ is the saturation vapour pressure, $e_{a}(\mathrm{kPa})$ is the natural vapour pressure, $e_{s}-e_{a}(\mathrm{kPa})$ is the saturation vapour pressure deficit, and $\Delta\left(\mathrm{kPa} /{ }^{\circ} \mathrm{C}\right)$ is the slope vapour pressure curve.

\subsection{Analysis of trends and change points}

The normality of meteorological and hydrological datasets was investigated with the Kolmogorov-Smirnov analysis as a first step before conducting change tests using 
statistical techniques. Depending on these tests, most meteorological and hydrological data series applied in this research do not follow a normal distribution at a significance level $p$ of 0.05 . Regarding the non-normal distribution attributes of datasets utilised in the current research, two widespread distribution-free non-parametric techniques (Pettitt test and Mann-Kendall (M-K) analysis) were applied to identify the variations of streamflow, precipitation, mean air temperature and potential evapotranspiration time series in the LZRB. The former was utilised for identifying monotonic trends or slow trends, whereas the latter was applied to identify sudden changes in the average level. A brief description of these two tests can be found below.

Firstly, for trend detection in the considered datasets, the Mann-Kendall analysis was considered. The $\mathrm{M}-\mathrm{K}$ analysis is a distribution-free technique for evaluating if there is a monotonic upward or downward trend of the considered parameter over time (Dahamsheh and Aksoy 2007; Seibert and Vis 2012). A monotonic downward (upward) trend indicates that the parameter consistently decreases (increases) during the studied time period. However, the trend might or might not be linear. The $\mathrm{M}-\mathrm{K}$ analysis can be applied instead of a parametric linear regression test, which can be used to analysis if the slope of the computed linear regression line is different from zero. The regression test requires that the residuals from the fitted regression line are normally distributed. Such an assumption is not required by the $\mathrm{M}-\mathrm{K}$ test, which is a non-parametric distribution-free test. For more details about the $\mathrm{M}-\mathrm{K}$ test, readers may refer to previous studies (Robaa and AL-Barazanji 2013; Seibert and Vis 2012).

Secondly, the Pettitt test has been applied for change point identification. Change point identifications are considered as important in the analysis of runoff datasets for the purpose of studying the impacts of anthropogenic interventions and climate change. The Pettitt test is a distribution-free method to calculate the existence change points for the average of a time series, if the specific change time is unidentified. This analysis has been commonly applied to assess alterations in hydrological and weather data (Velázquez et al. 2011; Zhang et al. 2001).

The PR-DCC can illustrate the consistency of runoff and precipitation data (Jiang et al. 2011). In general, the curve is a straight line. A variation in the trend of the curve could deduce that the properties of streamflow or precipitation have altered. The PR-DCC technique might be applied to test homogeneity of hydrological data and is often seen as an efficient tool for the detection of the hydrological system variations as a result of anthropogenic interventions (Huo et al. 2008; Velázquez et al. 2011; Zhang et al. 2001). As an auxiliary method for the change point detection in the precipitation and runoff series, the PR-DCC method was used in the current study.

By using change point test and trend analysis, the streamflow dataset is divided into a baseline period dataset and an anthropogenic interventions period dataset (Jiang et al. 2011). In this study, the Pettitt's test for change point identification of the streamflow time series is tested for reapproval of the change points identified using PR-DCC. Depending on the separated periods, the impacts of anthropogenic interventions and climate change on streamflow can be divided by using streamflow simulation methods as outlined in the next section.

\subsection{Rainfall-runoff simulation methods}

\subsubsection{Hydrological model descriptions}

For the purposes of planning, designing or management of river discharges, rainfall-runoff models have been used widely to acquire streamflow data since such data are not easily available. These models comprise of a series of equations that endeavour to mimic the diversity of the interrelated events, which participate in hydrological process. The hydrological models might be categorised based on many criteria such as procedure description, solution mechanism and scale. Various categories are applied in the literature, for example, lumped and distributed models, continuous-time and event-based models as well as conceptual and black-box models (Tigkas and Tsakiris 2004; Aksoy et al. 2016).

For the simulation of basin runoff depending on a set of weather parameters, the current research utilised three of the most commonly used conceptual models, which are the Medbasin rainfall-runoff, GR4J and HBV rainfall-runoff models (Tabari and Taalaee 2011; Tigkas et al. 2012). The Medbasin model integrates the two lumped hydrological models Medbasin-D and Medbasin-M for daily (D) and monthly (M) data, respectively, with tools for forecasting different climatic variations and drought scenarios. The Medbasin-M model is based on two calibration parameters, the total capacity of the soil storage $S_{\max }(\mathrm{mm})$ and the coefficient of deep percolation C. The monthly delay factor $a$ adjusts the distribution of the monthly runoff (Tigkas and Tsakiris 2004). A favourable computation of $S_{\max }(\mathrm{mm})$ can be accomplished by Eq. (3). Monthly precipitation P $(\mathrm{mm})$ and PET $(\mathrm{mm})$ data are utilised as input data for the rainfall-runoff modelling process.

$S_{\max }=25.4 \times\left(\frac{1000}{C N}-10\right)$

where $S_{\max }(\mathrm{mm})$ is the total capacity of the soil storage and $C N$ is the curve number that is based on many factors 
such as land use and land cover, previous moisture conditions in the basin and soil infiltrability.

The GR4J is a daily-lumped four parameter rainfallrunoff model that is used both for precipitation and potential evapotranspiration data as input for meteorological variables. The model belongs to the family of soil moisture accounting models, and shows a good robustness in comparative studies and was also extensively tested for various climatic regions including the USA, Australia and France. The model calibration is relatively simple because of the low number of parameters (Perrin et al. 2003).

The HBV is an example of a semi-distributed conceptual model simulating daily discharge depending on daily rainfall and air temperature and monthly estimates of potential evaporation as input. Air temperature data are used for calculating snow accumulation.

As a first step for simulation of runoff, the rainfallrunoff models were calibrated depending on the recorded dataset of the baseline period. Subsequently, the usual time series of streamflow was rebuild for the anthropogenic period. After that, the anthropogenic intervention impacts on streamflow have been estimated through subtracting the recorded streamflow from the rebuild streamflow as shown in Eq. (4).

$\Delta R_{\text {anthropogenic }}=R_{a}-R_{a r}$

where $\Delta R_{\text {anthropogenic }}(\mathrm{mm} / \mathrm{month})$ indicates the change in mean annual runoff as a result of the anthropogenic interventions effect, $R_{a}$ (mm/month) refers the observed runoff of the anthropogenic intervention period, and $R_{a r}$ ( $\mathrm{mm} / \mathrm{month})$ is the rebuild runoff series for the anthropogenic interventions period.

\subsubsection{Simple average method}

The simple average technique is considered the simplest method of combining the results of many single hydrological models (Ajami et al. 2006; Duan et al. 2007; Velázquez et al. 2011). An equal weight is assigned to the results of all of the considered models. This method can produce estimates that are better than those of the single models. The accuracy of the SAM method depends mainly on the number of models involved and on the actual estimating capability of the specific models included. The combined predicted streamflow $\mathrm{R}$ from $\mathrm{N}$ hydrological models can be computed by Eq. (5).

$R_{S A M_{t}}=\frac{1}{N} \sum_{j=1}^{N} R_{s i m_{i, t}}$

where $R_{S A M_{t}}$ is the multi-model streamflow simulated by $\mathrm{SAM}$ at time $\mathrm{t}, \mathrm{N}$ is the number of models under consideration and $R_{s i m_{i, t}}$ is the model streamflow simulation for i model and t time.

\subsubsection{Method of hydrologic sensitivity analysis}

The analysis of hydrologic sensitivity might be defined as the ratio variation in average streamflow in response to the average $\mathrm{P}$ and PET variations in an annual time step (Velázquez et al. 2011). The basin water balance can be expressed with Eq. (5). The change of $\Delta \mathrm{S}(\mathrm{mm})$ can reasonably be neglected on the average yearly time scale. It follows that $\Delta \mathrm{S}$ can be set as zero for a lengthy time period (i.e. 10 water years or more) (Guo et al. 2014; Jiang et al. 2014). Long-term average yearly actual evapotranspiration AET (mm) can be predicted by Eqs. (5) and (6) according to Zhang et al. (2001).

$P=E+R+\Delta S$

where $P(\mathrm{~mm})$ is precipitation, $E(\mathrm{~mm})$ represents evapotranspiration, $R(\mathrm{~mm})$ is streamflow, and $\Delta S(\mathrm{~mm})$ is basin water volume change. According to Zhang et al. (2001), long-term average annual actual evapotranspiration (AET) can be calculated as shown in Eq. (7).

$\frac{E}{P}=\frac{1+\omega \times \alpha_{k}^{-1}}{1+\omega \times \alpha_{k}^{-1}+\alpha_{k}}$

where $E(\mathrm{~mm})$ is evapotranspiration, $P(\mathrm{~mm})$ is precipitation, $w$ is the coefficient of the available water for plants related to the vegetation type (Zhang et al. 2001) and $\alpha_{k}^{i}$ is defined in Eq. (8).

$\alpha_{k}^{i}=\frac{\sum_{j=1}^{12} P_{i j}}{\sum_{j=1}^{12} P E T_{i j}} \quad i=1$ to $N$ and $j=1$ to 12

where $\alpha_{k}^{i}$ is the initial value $\left(\alpha_{k}\right)$ of RDI index; $P_{i j}(\mathrm{~mm})$ and $P E T_{i j}(\mathrm{~mm})$ are precipitation and potential evapotranspiration of the j-th month of the $\mathrm{i}$-th year; and $N$ is the overall number of years for the available data set.

The values of $\alpha_{k}$ match both the gamma and the lognormal distributions in various positions for various time scales for which they were examined, previously (Tigkas et al. 2012). Note that $\omega$ is the coefficient of plant-available water as a function of the crop type (Zhang et al. 2001). The parameter $\omega$ can be calibrated with the support of the annual long-term AET estimated from Eqs. (7) and (8). Precipitation perturbations and potential evapotranspiration can result in water balance alterations. Through considering a hydrologic sensitivity analysis, the average yearly streamflow alteration as a result of climate change can be predicted using Eq. (9) (Jiang et al. 2011).

$\Delta R_{\text {climate }}=\beta \times \Delta P+\gamma \times \Delta P E T$

where $\Delta R_{\text {climate }}(\mathrm{mm} / \mathrm{month}), \Delta P(\mathrm{~mm})$ and $\triangle P E T(\mathrm{~mm})$ 
indicate variations in streamflow, precipitation and potential evapotranspiration, respectively; $\beta$ and $\gamma$ are the streamflow coefficients of sensitivity to precipitation and potential evapotranspiration in this order, which can be expressed by Eqs. (10) and (11) (Li et al. 2007).

$\beta=\frac{1+2 \alpha_{12}^{-1}+3 \omega \alpha_{12}^{-1}}{\left(1+\alpha_{12}^{-1}+\omega\left(\alpha_{12}^{-1}\right)^{2}\right)^{2}}$

where $\beta$ is the streamflow coefficient of sensitivity to precipitation, $a_{12}$ is the 1 /annual dryness index and $w$ is the coefficient of available water for plants related to the vegetation category (Zhang et al. 2001).

$\gamma=-\frac{1+2 \omega \alpha_{12}^{-1}}{\left(1+\alpha_{12}^{-1}+\omega\left(\alpha_{12}^{-1}\right)^{2}\right)^{2}}$

where $\gamma$ is the streamflow coefficient of potential evapotranspiration, $w$ is the coefficient of plant-available water related to the vegetation category (Zhang et al. 2001) and $\alpha_{12}$ is the $1 /$ annual dryness index.

\subsubsection{Multi-regression method}

In this method, streamflow is integrated with $P$ and $P E T$ at a monthly time scale for the baseline time period as shown in Eq. (12). Based this equation, the natural streamflow of the anthropogenic interventions can be expressed as shown in Eqs. (13) and (14).

$R_{b}=a P_{b}+b P E T_{b}+c$

where $R_{b}\left(\mathrm{~m}^{3} / \mathrm{s}\right)$ refers to the baseline period observed streamflow; $P_{b}(\mathrm{~mm})$ and $P E T_{b}(\mathrm{~mm})$ represent the precipitation and potential evapotranspiration of the baseline period; and $a, b$, and $c$ are three constants predicted using least-square regression analysis.

$\overline{R_{a}}=a P_{a}+b P E T_{a}+c$

where $\overline{R_{a}}$ (mm/month) expresses the reconstructed streamflow for the anthropogenic intervention period; $P_{a}$ $(\mathrm{mm})$ and $P E T_{a}(\mathrm{~mm})$ represent the anthropogenic intervention period precipitation and potential evapotranspiration, respectively; and $a, b$, and $c$ are three parameters estimated using least-square regression analysis.

$\Delta R_{\text {anthropogenic }}=R_{a}-\overline{R_{a}}$

where $\Delta R_{\text {anthropogenic }}(\mathrm{mm} / \mathrm{month})$ indicates the average annual streamflow alteration owing to the anthropogenic intervention effects, $R_{a}(\mathrm{~mm} / \mathrm{month})$ represents the recorded streamflow subject to anthropogenic intervention period, and $\overline{R_{a}}(\mathrm{~mm} / \mathrm{month})$ indicates the change in mean annual runoff due to anthropogenic interventions.

\subsubsection{Model evaluation criteria}

The root mean square error (RMSE), statistical methods index of agreement (IoA), correlation coefficient (r), and coefficient of Nash-Sutcliffe (NSCE (Jones et al. 2004)) were used to assess the model performance (Eqs. (15) to (18)). Accordingly, the impacts of anthropogenic interventions and climate change on streamflow can be quantified as Eqs. (15) to (18).

$R M S E=\sqrt{\frac{1}{n} \sum_{i=1}^{n}\left[\left(R_{o b s}\right)_{i}-\left(R_{\text {sim }}\right)_{i}\right]^{2}}$

$I o A=1-\frac{\sum_{i=1}^{n}\left[\left(R_{o b s}\right)_{i}-\left(R_{\text {sim }}\right)_{i}\right]^{2}}{\sum_{i=1}^{n}\left[\left|\left(R_{o b s}\right)_{i}-\bar{R}_{o b s}\right|+\left|\left(R_{\text {sim }}\right)_{i}-\bar{R}_{\text {obs }}\right|\right]^{2}}$

$r=\sqrt{\frac{\sum_{i=1}^{n}\left[\left(R_{o b s}\right)_{i}-\bar{R}_{o b s}\right]\left[\left(R_{o b s}\right)_{i}-\bar{R}_{\text {sim }}\right]}{\left\{\sum_{i=1}^{n}\left[\left(R_{\text {obs }}\right)_{i}-\bar{R}_{\text {obs }}\right]\right\}^{0.5}\left\{\sum_{i=1}^{n}\left[\left(R_{\text {sim }}\right)_{i}-\bar{R}_{\text {sim }}\right]\right\}^{0.5}}}$

$N S C E=1-\frac{\sum_{i=1}^{n}\left[\left(R_{s i m}\right)_{i}-\left(R_{o b s}\right)_{i}\right]^{2}}{\sum_{i=1}^{n}\left[\left(R_{o b s}\right)_{i}-\overline{R_{o b s}}\right]^{2}}$

where RMSE is the root mean square error (dimensionless), IoA is the index of agreement (dimensionless), $r$ is the coefficient of correlation (dimensionless), $R_{o b s(i)}$ is the recorded streamflow (mm/month) at time step $i, R_{\operatorname{sim}(i)}$ is the predicted streamflow $(\mathrm{mm} / \mathrm{month})$ at time step i, $\overline{R_{o b s}}$ is the average amount of the recorded values ( $\mathrm{mm} / \mathrm{month}$ ), and $\mathrm{n}$ is the data point number.

\subsubsection{Separation effect framework}

The impacts of these two factors on streamflow can be estimated using the following equations:

$\Delta R_{\text {total }}=R_{a}-R_{b}$

$\Delta R_{\text {total }}=\Delta R_{\text {anthropogenic }}+\Delta R_{\text {climate }}$

$E_{\text {anthropogenic }}=\frac{\Delta R_{\text {anthropogenic }}}{\left|\Delta R_{\text {total }}\right|} \times 100 \%$

$E_{\text {climate }}=\frac{\Delta R_{\text {climate }}}{\left|\Delta R_{\text {total }}\right|} \times 100 \%$

where $\Delta \mathrm{R}_{\text {total }}(\mathrm{mm} / \mathrm{month})$ is the total change of streamflow, $R_{a}$ (mm/month) represents the streamflow subject to anthropogenic interventions, $R_{b}(\mathrm{~mm} / \mathrm{month})$ refers to the baseline period observed streamflow, $\Delta R_{\text {anthropogenic }}$ ( $\mathrm{mm} / \mathrm{month})$ indicates the average annual streamflow alteration owing to the anthropogenic intervention effects, $\Delta R_{\text {climate }}(\mathrm{mm} / \mathrm{month})$ indicates variations in streamflow, $E_{\text {anthropogenic }}(\%)$ expresses the impact of anthropogenic interventions on streamflow, $\mid \Delta \mathrm{R}_{\text {total }} l$ indicates the absolute 
value of $\Delta \mathrm{R}_{\text {total }}$.and $E_{\text {climate }}(\%)$ indicates the impact of climate change on streamflow.

\section{Results and discussion}

\subsection{Long-term meteorological and hydrological data changes}

Long-term trends in hydrological processes are potentially influenced by changing climate and anthropogenic interventions (Al-Ansari 2013; Al-Ansari et al. 2014). Investigating such trends might support the identification of anthropogenic intervention starting points. Yearly mean air temperature, precipitation, potential evapotranspiration and streamflow data were analysed applying the $\mathrm{M}-\mathrm{K}$ test to detect long-term trends for the time period between 1979 and 2013.

During the last 35 analysed years, the whole LZRB displayed a rising trend of mean air temperature with a maximum value of $+0.67 \mathrm{C}^{\circ}$ for one decade, while a declining precipitation trend (Fig. 2) with a maximum decrease of $151 \mathrm{~mm}$ per decade was noted. The LZRB yearly precipitation is around $720 \mathrm{~mm}$. The maximum precipitation (1222 mm) was recorded for 1987/1988, while the corresponding minimum $(250 \mathrm{~mm})$ was assigned to $2007 / 2008$ (Fig. 2). The mean annual precipitation changed spatially from $56 \mathrm{~mm}$ at Kirkuk station to $1369 \mathrm{~mm}$ at Sulymaniya station. The upper basin had higher precipitation values than the lower one.

An evident trend of air temperature increase during the last half century led to a significant increase in the potential evapotranspiration for the entire LZRB. Based on the trend analysis (Table 4), the increase in PET rate was $39 \mathrm{~mm}$ per decade. With an average value of $1065.3 \mathrm{~mm}$, the computed potential evapotranspiration for the basin changed from $962 \mathrm{~mm}$ in $1982 / 1983$ to $1110 \mathrm{~mm}$ in $2007 / 2008$ (Fig. 2).

The obtained results indicate that the climate in the studied region is getting warmer and drier. The annual precipitation decreased. The yearly average air temperature increased and the annual runoff depth decreased. These findings are largely in agreement with previous studies (AlAnsari 2013; Al-Ansari et al. 2014; Fadhil 2010; Robaa and AL-Barazanji 2013).

The coefficient of runoff is expressed as the percentage of the streamflow compared to the precipitation over a specific time period, and has been selected to represent the LZRB hydro-climatic conditions (Fig. 3). The corresponding coefficient of runoff for the entire period of study was 0.22 . A declining trend at a rate of -0.009 per decade was noted. The decline in the coefficient of runoff (Fig. 3) indicates that the streamflow yield has become weaker during the last four decades as estimated previously (AlAnsari 2013; Al-Ansari et al. 2014).

\subsection{Hydrological variable change point detection}

The upstream annual runoff of the LZRB has an average of $169 \mathrm{~m}^{3} / \mathrm{s}$ for the 35-year hydrological period (1979 to 2013). The minimum was $54 \mathrm{~m}^{3} / \mathrm{s}$ for the water year 2007/2008. Nearly $436 \mathrm{~m}^{3} / \mathrm{s}$ were noted as the maximum for the year 1987/1988 (Fig. 2). Over the studied time period, mean streamflow runoff of the LZRB exhibited a significant decline $(-0.334$ at $\alpha=95 \%)$ decline at a rate of $-38 \mathrm{~m}^{3} / \mathrm{s}$ per decade.

The annual runoff change point series was determined using the Pettitt and PR-DCC tests. Figures 4 and 5 show the change point years of the runoff and precipitation time series for the Pettitt and PR-DCC methods, respectively. The water
Fig. 2 Annual values and trends of a mean air temperature and precipitation; and b potential evapotranspiration (PET) and runoff in Lower Zab River basin for the time period between 1979 and 2014
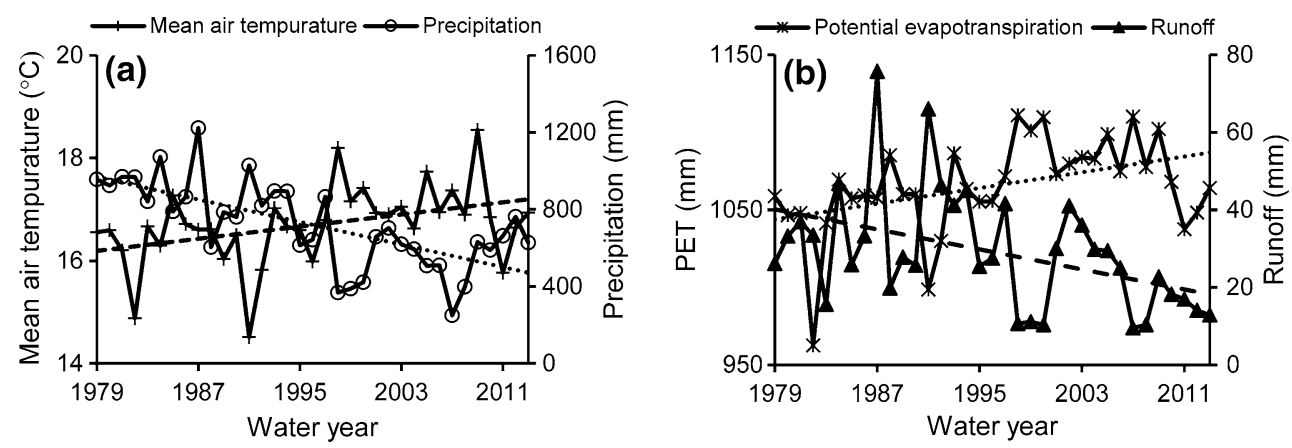
Table 4 Statistical properties of the meteorological variables after applying a non-parametric test for the decadal change

\begin{tabular}{|c|c|c|c|c|c|c|}
\hline \multirow[t]{2}{*}{ Station name } & \multicolumn{2}{|c|}{ Mean air temperature $\left({ }^{\circ} \mathrm{C}\right)$} & \multicolumn{2}{|c|}{ Precipitation (mm) } & \multicolumn{2}{|c|}{ Potential evapotranspiration $(\mathrm{mm})$} \\
\hline & $\mathrm{M}-\mathrm{K}^{\mathrm{a}}$ & $P$ value & $\mathrm{M}-\mathrm{K}^{\mathrm{a}}$ & $P$ value & $\mathrm{M}-\mathrm{K}^{\mathrm{a}}$ & $P$ value \\
\hline Kirkuk & $0.422 * *$ & $<0.01$ & $-0.553 * *$ & $<0.01$ & $0.420 * *$ & $<0.01$ \\
\hline Chem-Chamal & $0.345 * *$ & $<0.01$ & $-0.412 * *$ & $<0.01$ & 0.139 & 0.24 \\
\hline Sulymanya & $0.358 * *$ & $<0.01$ & $-0.301 * *$ & $<0.01$ & 0.201 & 0.09 \\
\hline Halabcha & $0.572 * *$ & $<0.01$ & $-0.522 * *$ & $<0.01$ & $0.316 * *$ & $<0.01$ \\
\hline Makhmoor & $0.462 * *$ & $<0.01$ & $-0.536^{* *}$ & $<0.01$ & 0.243 & 0.04 \\
\hline Salahddin & $0.452 * *$ & $<0.01$ & $-0.472 * *$ & $<0.01$ & 0.220 & 0.06 \\
\hline Erbeel & $0.351 * *$ & $<0.01$ & $-0.371 * *$ & $<0.01$ & 0.203 & 0.09 \\
\hline Soran & $0.380 * *$ & $<0.01$ & $-0.426^{* *}$ & $<0.01$ & $0.241 *$ & 0.05 \\
\hline Mahabad & $0.603 * *$ & $<0.01$ & $-0.573 * *$ & $<0.01$ & $0.525 * *$ & $<0.01$ \\
\hline Sachez & 0.079 & 0.50 & $-0.328 * *$ & 0.01 & 0.193 & 0.10 \\
\hline
\end{tabular}

Negative (-) and positive values indicate the decreasing and increasing trends, respectively

** Correlation is significant at the 0.01 level (2-tailed); and

* Correlation is significant at the 0.05 level (2-tailed)

${ }^{a}$ Mann-Kendall non-parametric test

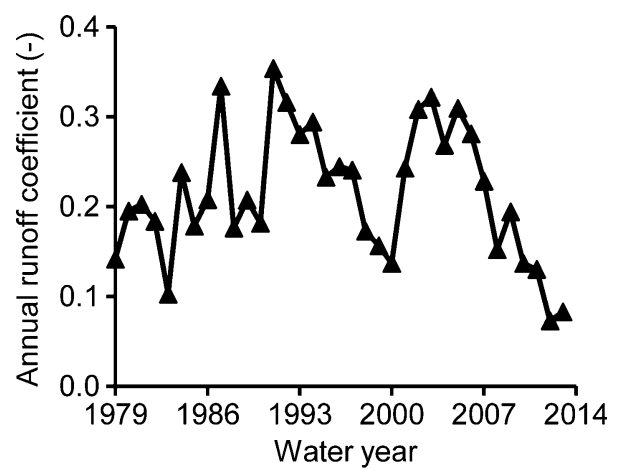

Fig. 3 Annual runoff coefficient for the 1979-2014 period in Lower Zab River basin

year 1997/1998 is considered as a change point for the studied time series. The obtained results are found to be consistent with the findings of many other researchers with respect to this study area. For example, Sen et al. (2012) explained through an analysis based on NCEP/NCAR reanalysis data that due to climate change the study region witnessed a statistically $(\mathrm{p}<0.05)$ significant shift in the streamflow during the same period of time. In addition, Bozkurt and Sen (2012) investigated the hydro-climatic effects of future climate change in the study region using the results of different dynamically down-scaled GCM (ECHAM5, CCSM3 and HadCM3) emission scenario (A1FI, A2 and B1) simulations. They found that the annual surface runoff of the headwater area declined dramatically by about 25 to $55 \%$ ).

The aggregate yearly runoff and precipitation shown in Fig. 5a indicates that before 1997, runoff and precipitation were relatively regular, but after 1997, the properties of runoff or precipitation altered. Integrating the PR-DCC analysis and the Pettitt test, the year 1997 could be seen as the change point reflecting the impact of both climate change and anthropogenic interventions on runoff and precipitation. Accordingly, the period between 1979 and 1997 was considered as the baseline period during which the anthropogenic interventions impacted on runoff were less recognisable. In order to fully appreciate the effects of climate and other influences on streamflow over the two periods, the variations in the correlation of streamflow and precipitation were investigated (Fig. 5b).

The period from 1998 to 2013 was seen as the anthropogenic intervention period, and was grouped into three hydrological sub-periods: 1998-2002, 2003-2008 and 2009-2013. For these hydrological periods, changes in average yearly streamflow, precipitation, and PET were estimated (Table 5). During the periods 1998-2002, 2003-2008 and 2009-2013, the mean annual precipitation declined by $-42,-43$ and $-30 \%$, and the potential evapotranspiration increased by $4,3.5$ and $1 \%$, whereas streamflow decreased by $-44,-37$ and $-55 \%$ in this order.

The runoff intra-annual alteration is associated with the monthly cycle of precipitation, mean air temperature and catchment water-related non-climatic drivers. In order to further comprehend the intra-annual availability of streamflow and precipitation, the mean monthly precipitation and streamflow data between the baseline period (1979-1997) and the anthropogenic intervention period (1998-2013) have been compared with each other (Fig. 6). Noticeable changes in both precipitation and streamflow were seen for the two considered time periods. The average monthly precipitation and streamflow between 1998 and 2013 declined compared with the corresponding data for the baseline period. The decreases were greatest for June, 
Fig. 4 Pettitt test for detecting a change in the annual: a precipitation; and $\mathbf{b}$ runoff
Fig. 5 a Precipitation-runoff DCC) of annual precipitation and runoff in the Lower Zab River basin; $\mathbf{b}$ and correlation between precipitation and runoff for the two considered time period double cumulative curve (PR-
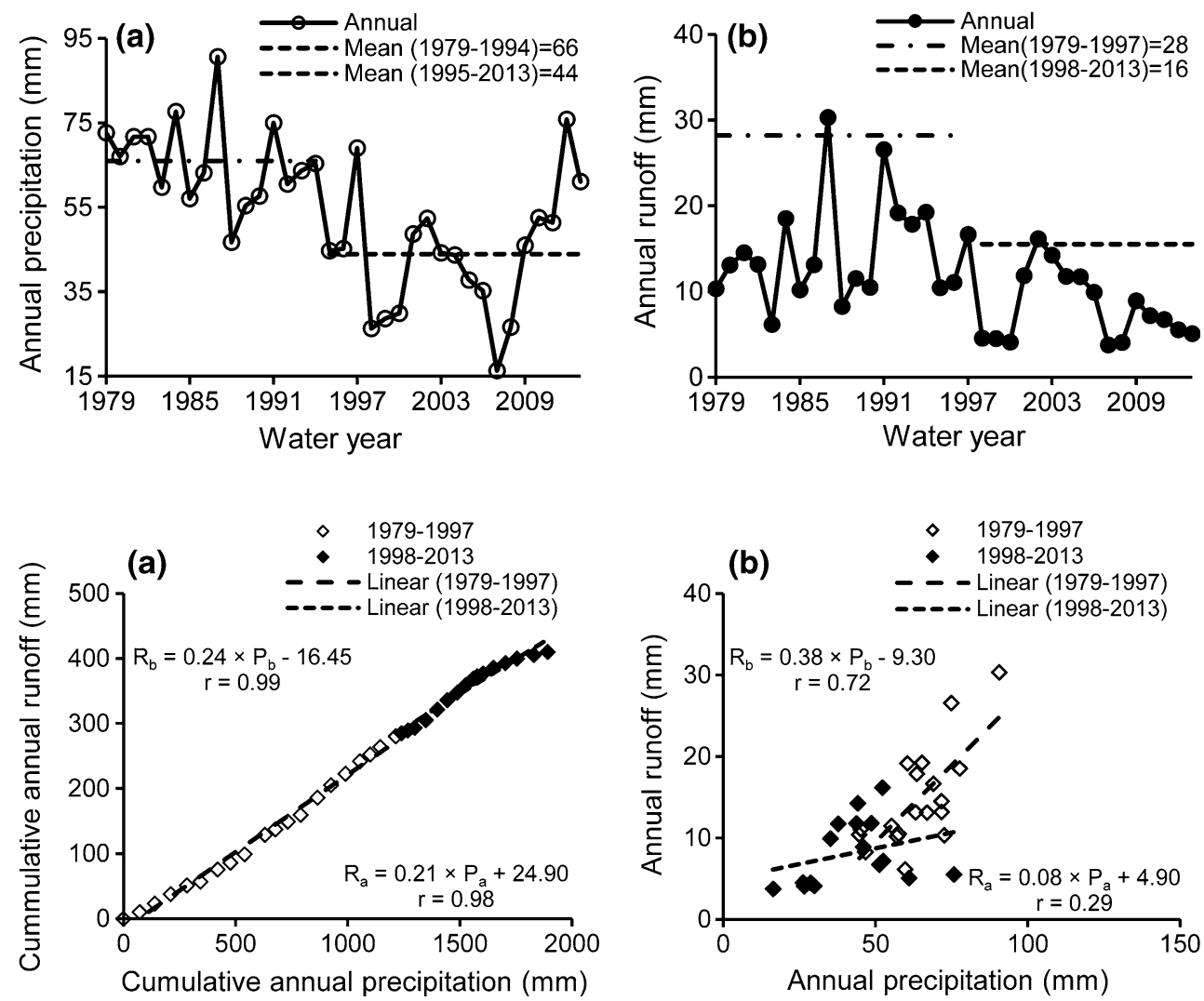

Table 5 Changes in mean annual precipitation, potential evapotranspiration and runoff during recent hydrological time periods

\begin{tabular}{lllll}
\hline Duration & Unit & 1998-2002 & 2003-2008 & 2009-2013 \\
\hline Precipitation & $\mathrm{mm} / \mathrm{a}$ & 507 & 496 & 611 \\
& Change in mm/a & -83.98 & -36.3 & -90.9 \\
& Relative change in \% & -42 & -43 & -30 \\
Potential evapotranspiration & $\mathrm{mm} / \mathrm{a}$ & 1106 & 1088 & 1064 \\
& Change in mm/a & -7.79 & 6.53 & -9.51 \\
& Relative change in \% & +4 & +3.5 & +1 \\
\multirow{3}{*}{ Recorded runoff } & mm/a & 8 & 9 & 7 \\
& Change in mm/a & -2.90 & -2.67 & -0.96 \\
& Relative change in \% & -44 & -37 & -55 \\
\hline
\end{tabular}

July and August (irrigation season), and were smallest during the winter months. Hence, the decrease in streamflow within the post-alteration period might be due to basin-related non-climate drivers as indicated in the past (Al-Ansari 2013; Al-Ansari et al. 2014). The application of the same statistical methods for a case study in Northern China was similarly successful (Jiang et al. 2011).

\subsection{Calibration and validation}

\subsubsection{Overview}

Over the baseline time period, few anthropogenic interventions impacted on streamflow within the LZRB.
Accordingly, it was treated as a baseline to compute the climate change impacts and anthropogenic interventions on streamflow for the non-climate drivers' period utilising the considered techniques. Figure 7 displays scatter diagram relationships between monthly runoff and precipitation for the time periods 1979-1997 $(\mathrm{r}=0.50)$ and 1998-2013 $(\mathrm{r}=0.44)$. The correlation between monthly runoff and precipitation for 1979-1997 is better than that for 1998-2013. Additionally, the coefficients of runoff for the baseline period were more than the ones for the climate change and anthropogenic intervention periods. The obtained results demonstrated that the runoff was considerably affected by drought events due to climate change linked with upstream non-climatic drivers such as river 
Fig. 6 Average monthly a precipitation and $\mathbf{b}$ runoff for the baseline (1979-1997) and the altered periods between 1998 and 2013
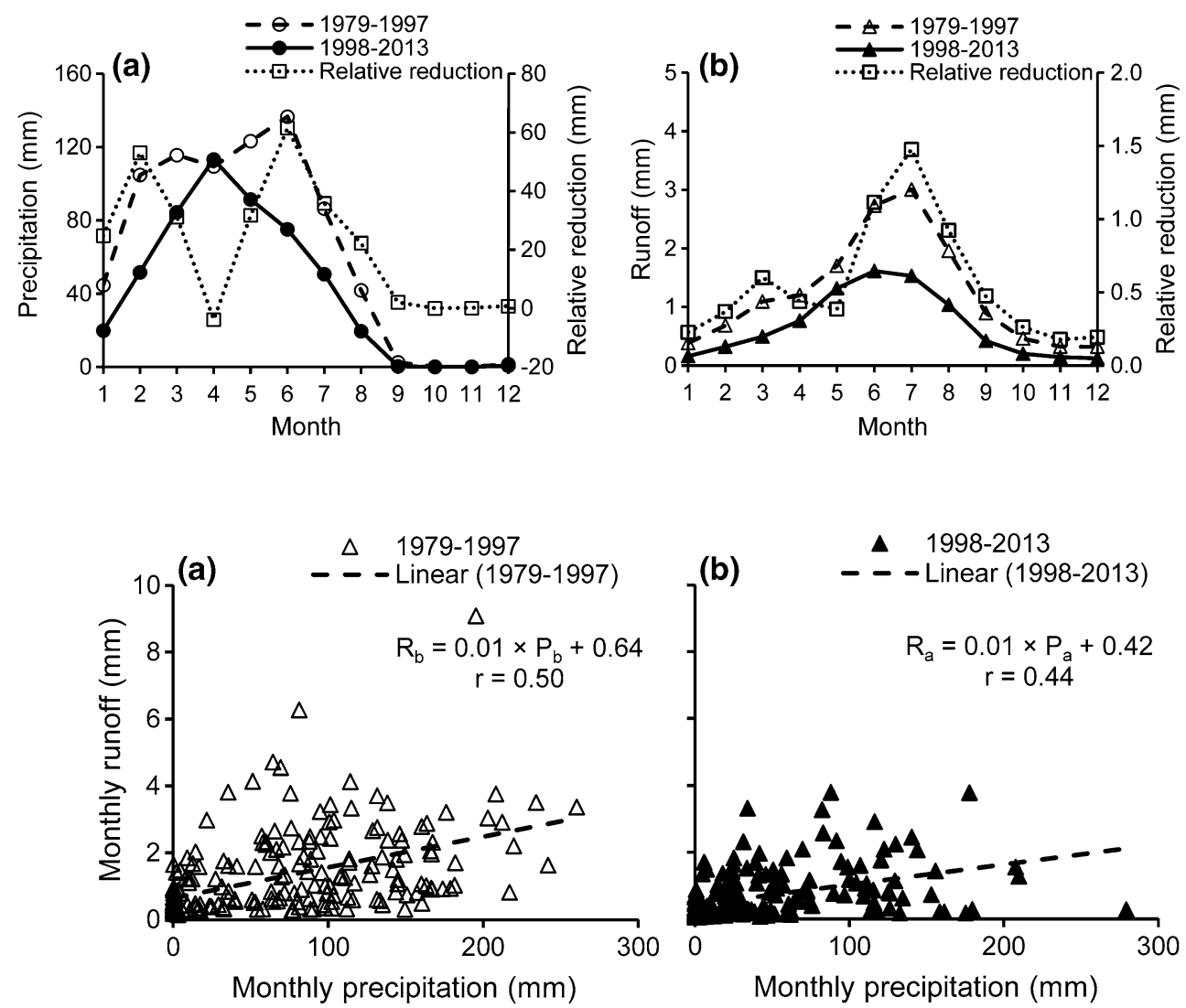

Fig. 7 Monthly relationship between precipitation and runoff for the a 1979-1997, and b $1998-2013$ periods regulation, land use changes, water withdrawal and interbasin water transfer schemes (Al-Ansari 2013; Al-Ansari et al. 2014).

\subsubsection{The multi-regression equation}

Depending on the monthly precipitation and PET of the baseline period, a multi-regression equation was developed as indicated by Eq. (23).

$R=0.013 \times P+0.0034 \times P E T-0.05$

where $R(\mathrm{~mm})$ is the monthly streamflow, $P(\mathrm{~mm})$ is precipitation, and PET (mm) represents the potential evapotranspiration.

Figure $8 \mathrm{a}, \mathrm{b}$ indicate good promise between monthly recorded and predicted streamflow data applying Eq. (23) for the Dokan hydrologic station during the considered time periods 1979-1997 and 1998-2013, respectively. The value of the coefficient of correlation was 0.52 at a significance level of 0.001 . The NSCE coefficient was 0.30 . The obtained measures of performance show that the multiregression model might not predicted streamflow precisely. The natural runoff series was rebuilt after considering the precipitation and PET of the anthropogenic interventions period as input. Using the rebuild runoff time series, the impacts of human activities and climate variability on streamflow were tested.

\subsubsection{Method for the hydrologic sensitivity analysis}

The coefficient of plant-available water to crop type $w$ is the main variable in the hydrologic sensitivity analysis. This parameter has been calibrated through equating longterm annual AET computed using Eq. (9) and the baseline period for the water balance Eq. (1979-1997). Considering $w=1$, the outcomes of yearly AET predicted by Eq. (9) are acceptable and reasonable (Fig. 9). Thus $w=1$ has been specified for the LZRB. When $w$ is set to 1 , the coefficients of sensitivity values $\frac{\partial R}{\partial P}$ and $\frac{\partial R}{\partial P E T}$ (where $R$ (mm/month) is the monthly streamflow) were 0.0167 and 0.0141 in this order, which indicate that the runoff change was more subtle to precipitation compared to potential evapotranspiration.

\subsubsection{Method of hydrologic simulation}

The calibration time period for the hydrologic model was 1988-1999, while 1979-1986 was the validation period. The obtained results from the three used models show a good promise between monthly recorded and predicted 

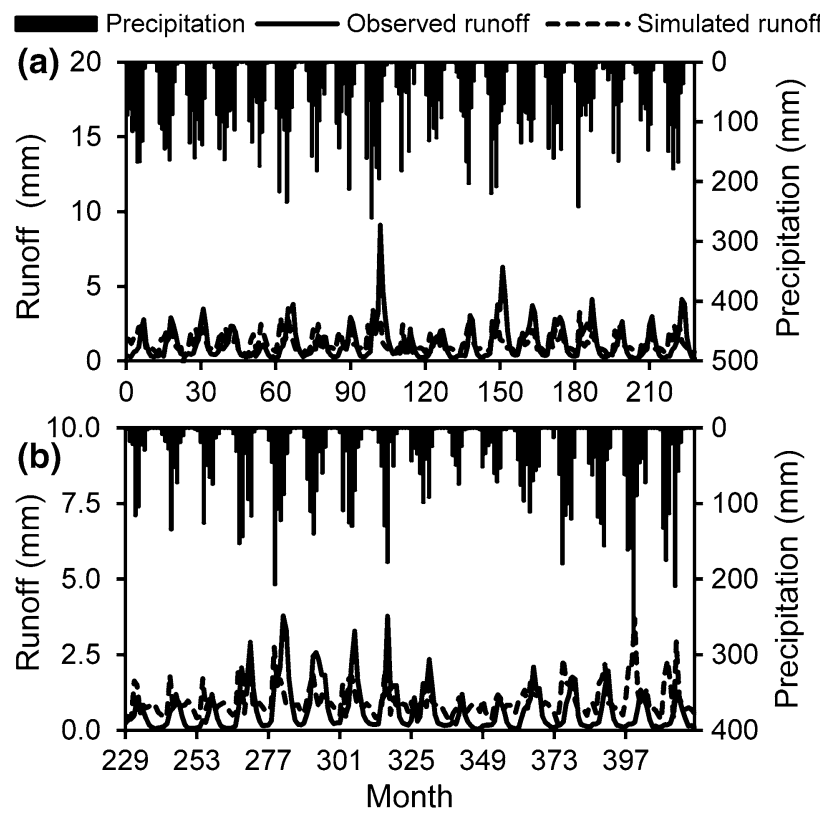

Fig. 8 Monthly observed and simulated runoff by multi-regression method at the Dokan hydrologic station for the a 1979-1997; and b 1998-2013 periods, respectively

runoff data at the Dokan hydrologic station from 1979 to 1997 (Fig. 10a). Table 6 shows the performance measures for the calibration and validation time periods using the GR4J, Medbasin and HBV simulation models. The calibrated rainfall runoff model was used to rebuild the streamflow datasets for the anthropogenic interventions period between 1998 and 2013 (Fig. 10b) with actual weather and hydrologic input data. With the rebuild streamflow dataset of the anthropogenic intervention period and the corresponding recorded streamflow dataset, it makes it possible to quantitatively assess the impacts of non-climate drivers and climate variability on streamflow.

Figures $8 \mathrm{~b}$ and $10 \mathrm{~b}$ compared recorded and predicted streamflow data for the Dokan hydrologic station for the

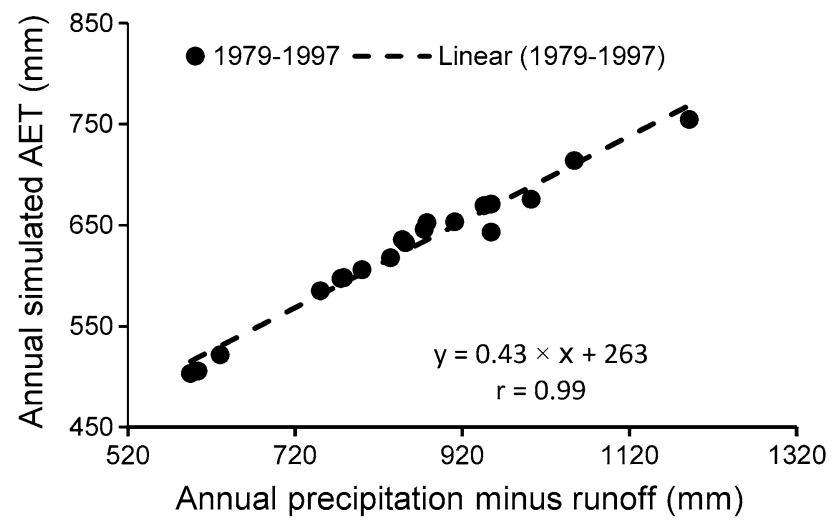

Fig. 9 Scatter diagram and correlation of annual actual evapotranspiration (AET) estimated from a water balance equation and predicted using Eq. (6) for the time period between 1979 and 1997 hydrological years between 1998 and 2013. The impacts of anthropogenic interventions and climate variability on streamflow were assessed depending on both the conceptual framework and the simulated findings of the various applied models. The simulation methods provided relatively consistent computations of the mean streamflow ratio change for the hydrological period between 1998 and 2013 (Table 7). The data show that climate change makes the greatest impact. These findings are in broad agreements with previous estimations (Ajami et al. 2006; Al-Ansari 2013).

\subsection{Comparison of simple average method and single model predictions}

In order to examine the simple average method performance, firstly, a set of numerical experiments were computed using the three hydrological models. Figure 11a shows the linear regression between observed and simulated runoff for various model predictions regarding the Dokan hydrological station. Figure $11 \mathrm{~b}$ reveals that HBV is the best model in terms of correlation coefficient, whereas the Medbasin model is the weakest. Then the SAM has been utilised to estimate the streamflow (Fig. 11b). Figure 11 reveals that the statistics from the single model simulations are almost always worse than those of the SAM, W and B simulations. The results confirm that just simply averaging the single model simulations would lead to an enhancement of the simulation level of accuracies, which is consistent with previous research
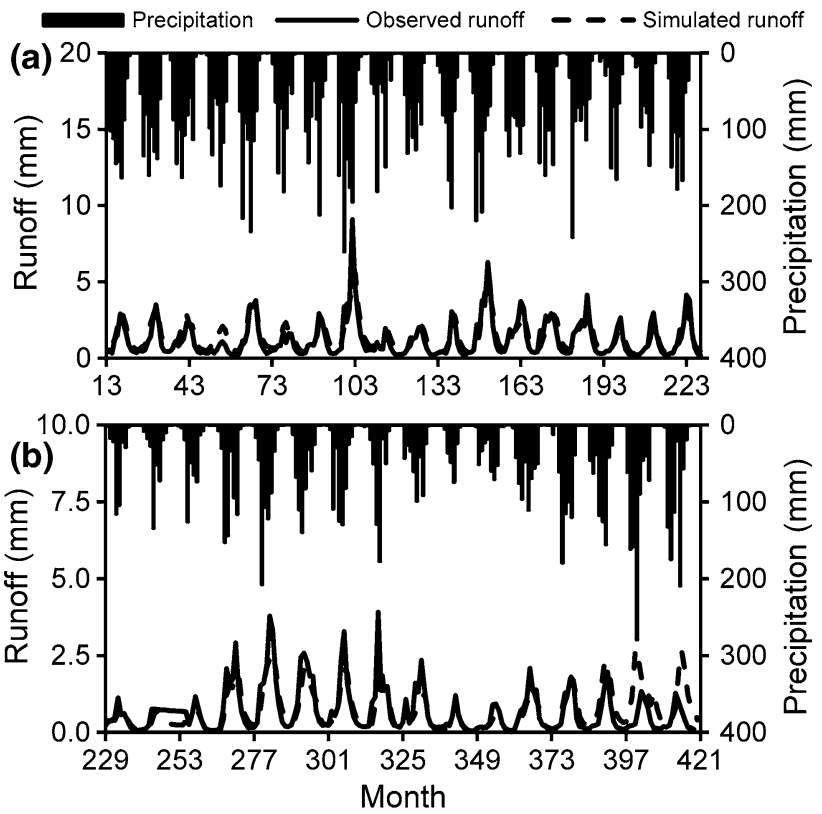

Fig. 10 Monthly observed and simulated runoff using SAM multimodel technique at the Dokan hydrological station for the a 1979-1997; and b 1998-2013 periods 
Table 6 Performance measures for the calibration and validation time periods using the GR4J, Medbasin, and HBV simulation models

\begin{tabular}{llllll}
\hline \multirow{2}{*}{ Model } & Time period & \multicolumn{4}{l}{ Statistical performance } \\
\cline { 3 - 6 } & & RMSE $^{\mathrm{a}}$ & $\mathrm{IoA}^{\mathrm{b}}$ & $\mathrm{R}^{\mathrm{c}}$ & $\mathrm{NSCE}^{\mathrm{d}}$ \\
\hline \multirow{2}{*}{ Medbasin } & Calibration & 2.69 & 0.96 & 0.94 & 88 \\
& Validation & 5.99 & 0.66 & 0.50 & 83 \\
\multirow{2}{*}{ GR4J } & Calibration & 0.79 & 0.90 & 0.82 & 67 \\
& Validation & 1.00 & 0.90 & 0.84 & 50 \\
\multirow{2}{*}{ HBV } & Calibration & 0.542 & 0.99 & 0.89 & 80 \\
& Validation & 0.446 & 0.99 & 0.94 & 50 \\
\hline
\end{tabular}

${ }^{a}$ Root mean square error

b Index of agreement

${ }^{c}$ Correlation coefficient

d Nash-Sutcliffe coefficient

(Ajami et al. 2006; Georgakakos et al. 2004). Hence, excluding the worst performing model leads to an improvement of the correlation compared to the single hydrological model.

Furthermore, hydrological parameters such as flowrate are known to have a special annual cycle. The hydrologic model simulation accuracies for different months often mimic this yearly cycle (Fig. 12), which shows the performance of the individual model simulations for the studied basin during various months for the two considered time periods. Figure 12 reveals that a model might perform well for some months, but poorly for other months, when compared to competing models.

Accordingly, the use of multi-model simulations leads to the question of how the accuracy of a single model influences the accuracy of the results. To address this question, the best performing model (B) and the worst performing one (W) were sequentially removed from consideration. The obtained results are shown in Fig. 13, which indicates that the inclusion of all the calibrated models is necessary to obtain consistently good simulation results. This is because eliminating the best performing model would actually deteriorate the outcome (Fig. 13b). However, excluding the worst performing model would enhance the monthly runoff (Fig. 13a). This leads to the conclusion that the accuracy level of a single model can impact on the overall accuracy of the multi-model combination simulation. This confirms that the application of the SAM in runoff estimation might produce values that are
Table 7 Climate change and anthropogenic interventions impacts on mean annual runoff (R) during recent hydrological periods using different rainfallrunoff simulation methods

\begin{tabular}{|c|c|c|c|c|c|}
\hline \multicolumn{2}{|l|}{ Duration } & \multirow{2}{*}{$\frac{\text { Unit }}{\mathrm{mm} / \mathrm{a}}$} & \multirow{2}{*}{$\frac{1998-2002}{-6.54}$} & \multirow{2}{*}{$\frac{2003-2008}{-5.52}$} & \multirow{2}{*}{$\frac{2009-2013}{-8.08}$} \\
\hline Runoff total alteration & & & & & \\
\hline \multirow[t]{4}{*}{ Multi-regression method } & $\Delta \mathrm{R}_{\text {anthropogenic }}$ & $\mathrm{mm} / \mathrm{a}$ & -1.93 & -1.88 & -0.97 \\
\hline & & $\%$ & -30 & -34 & -12 \\
\hline & $\Delta \mathrm{R}_{\text {climate }}$ & $\mathrm{mm} / \mathrm{a}$ & -4.61 & -3.64 & -7.11 \\
\hline & & $\%$ & -71 & -66 & -88 \\
\hline \multirow[t]{4}{*}{ Hydrological sensitivity } & $\Delta \mathrm{R}_{\text {anthropogenic }}$ & $\mathrm{mm} / \mathrm{a}$ & -1.94 & 1.41 & 3.27 \\
\hline & & $\%$ & -30 & -26 & -40 \\
\hline & $\Delta \mathrm{R}_{\text {climate }}$ & $\mathrm{mm} / \mathrm{a}$ & 4.60 & 4.10 & 4.81 \\
\hline & & $\%$ & -70 & -74 & -60 \\
\hline \multirow[t]{4}{*}{ Medbasin model } & $\Delta \mathrm{R}_{\text {anthropogenic }}$ & $\mathrm{mm} / \mathrm{a}$ & -0.29 & -0.67 & -2.36 \\
\hline & & $\%$ & -4 & -12 & -29 \\
\hline & $\Delta \mathrm{R}_{\text {climate }}$ & $\mathrm{mm} / \mathrm{a}$ & -6.25 & -4.85 & -5.72 \\
\hline & & $\%$ & -96 & -88 & -71 \\
\hline \multirow[t]{4}{*}{ GR4J model } & $\Delta \mathrm{R}_{\text {anthropogenic }}$ & $\mathrm{mm} / \mathrm{a}$ & -1.03 & -0.72 & -0.43 \\
\hline & & $\%$ & -16 & -14 & -5 \\
\hline & $\Delta \mathrm{R}_{\text {climate }}$ & $\mathrm{mm} / \mathrm{a}$ & -5.51 & -4.73 & -7.65 \\
\hline & & $\%$ & -84 & -86 & -95 \\
\hline \multirow[t]{4}{*}{ HBV model } & $\Delta \mathrm{R}_{\text {anthropogenic }}$ & $\mathrm{mm} / \mathrm{a}$ & -0.60 & -0.14 & -3.10 \\
\hline & & $\%$ & -9 & -3 & -38 \\
\hline & $\Delta \mathrm{R}_{\text {climate }}$ & $\mathrm{mm} / \mathrm{a}$ & -5.94 & -5.38 & -4.98 \\
\hline & & $\%$ & -91 & -97 & -62 \\
\hline \multirow[t]{4}{*}{$\mathrm{SAM}^{\mathrm{a}}$} & $\Delta \mathrm{R}_{\text {anthropogenic }}$ & $\mathrm{mm} / \mathrm{a}$ & -0.35 & -0.23 & -0.69 \\
\hline & & $\%$ & -5 & -4 & -8 \\
\hline & $\Delta \mathrm{R}_{\text {climate }}$ & $\mathrm{mm} / \mathrm{a}$ & -6.19 & -5.29 & -7.39 \\
\hline & & $\%$ & -95 & -96 & -92 \\
\hline
\end{tabular}

\footnotetext{
${ }^{\text {a }}$ Simple average method
} 

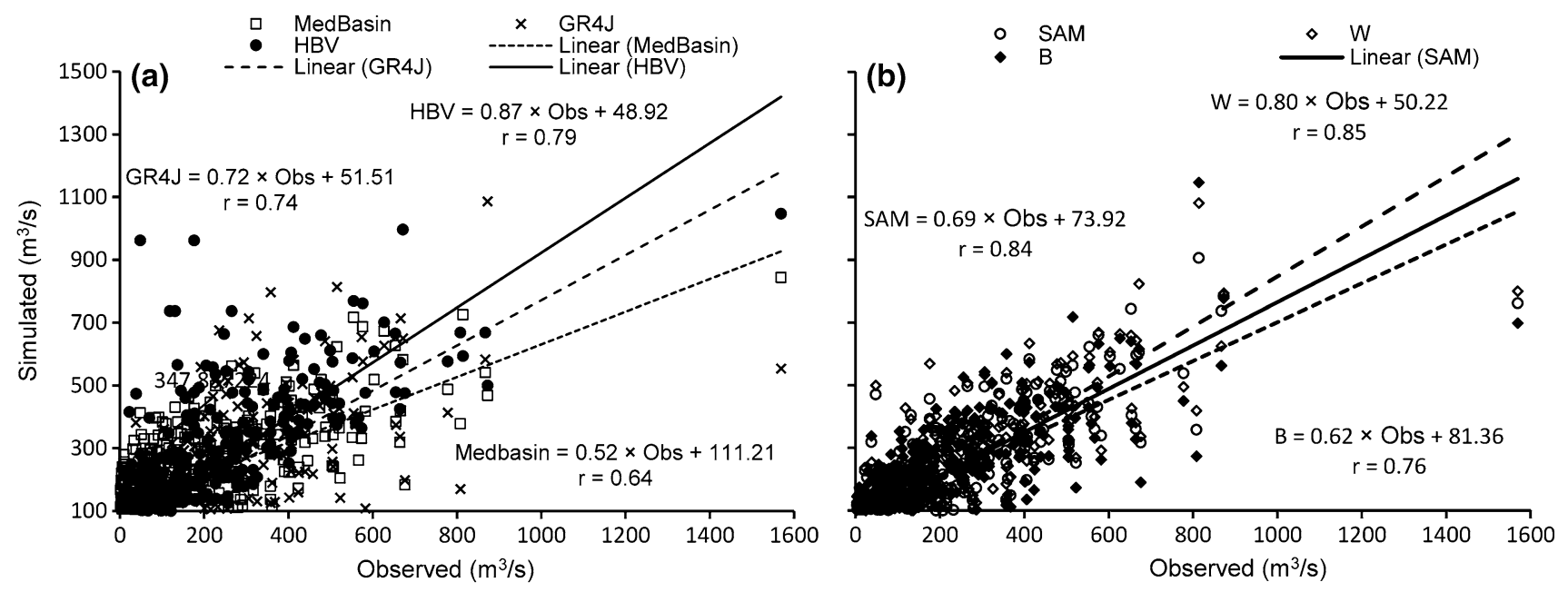

Fig. 11 Linear regression between observed and simulated runoff: a Medbasin, GR4J and HBV models; b simple average model (SAM), excluding the best model (B) and the worst model (W) simulation results, for the Dokan hydrological station

Fig. 12 Monthly observed (Obs) and simulated runoff using Medbasin, GR4J, and HBV models at the Dokan hydrological station for the a 1979-1997; and b 1998-2013 periods
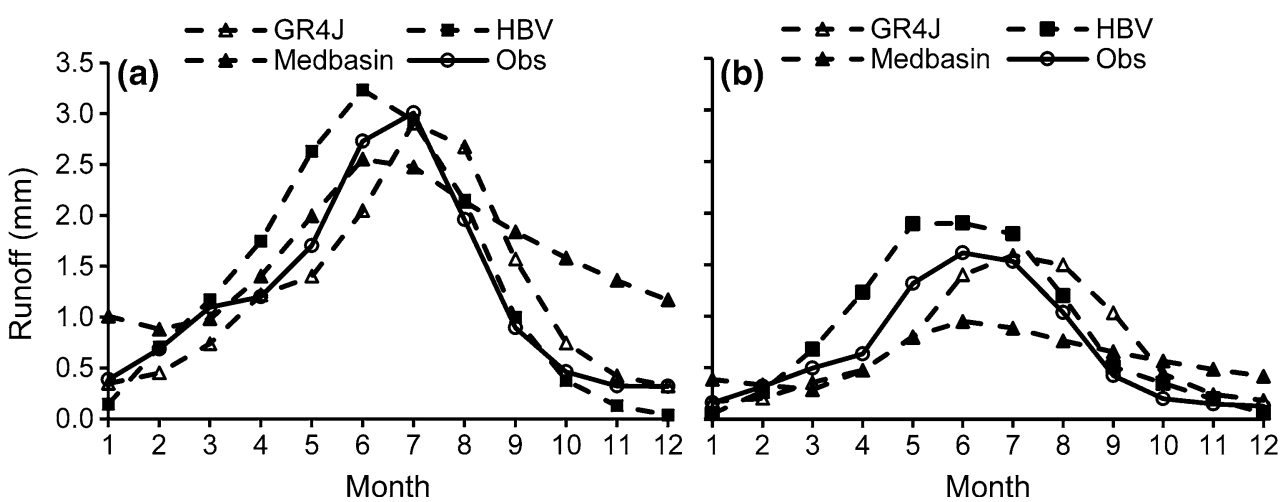

more precise than the results from the best of the three considered models, which justifies the implementation of the multi-model technique in the context of rainfall-runoff modelling.

Furthermore, there is a considerable change in the magnitude and timing of the peak discharge occurring between two time periods (Fig. 13). The monthly discharge differences between two periods illustrate decreases mostly in May. The change in streamflow timing is mainly a result of anthropogenic intervention. The obtained results regarding the shift in the magnitude and the timing of the river discharge are consistent with the results obtained from others within the study area (Cullen and deMenocal 2000; Sen et al. 2012).

\section{Conclusions and recommendations}

The surface runoff in the LZRB has declined considerably as a result of climate variability and anthropogenic interventions. In order to evaluate the impacts of these two factors on the river flow over the study basin, hydrologic models simulation, hydrologic sensitivity analysis and multi-regression have been successfully applied.

The study outcomes indicate that the aggregated precipitation between October and May, which are the wet months, accounts for nearly $99.5 \%$ of the total annual precipitation. In contrast, the aggregated precipitation contributes only to nearly $0.5 \%$ of the entire precipitation during the dry months, which are June to September.

The hydrological periods 1998-2002 and 2006-2008 witnessed a sharp decline in the average precipitation for the studied basin, which in turn caused a reduction in the streamflow by more than $80 \%$. This statistically significant alteration during the non-rainy months attributed to the influence of both anthropogenic interventions and climate variability pressure to the upper part of the case study area, which in turn decreased the watershed storage system availability. An abrupt change reflecting the climate change impacts on streamflow was recorded for the year 1997. This change was due to the rapid anthropogenic developments in the basin. During the hydrological years between 1998 and 2013 , the mean annual runoff declined by $95 \%$ compared with the baseline period from 1979 to 1997 . 
Fig. 13 Monthly observed (Obs) and simulated runoff using simple average method (SAM), excluding the best model (B) results and eliminating the worst model results (W) for the Dokan hydrological station for the a 1979-1997; and b 1998-2013 periods

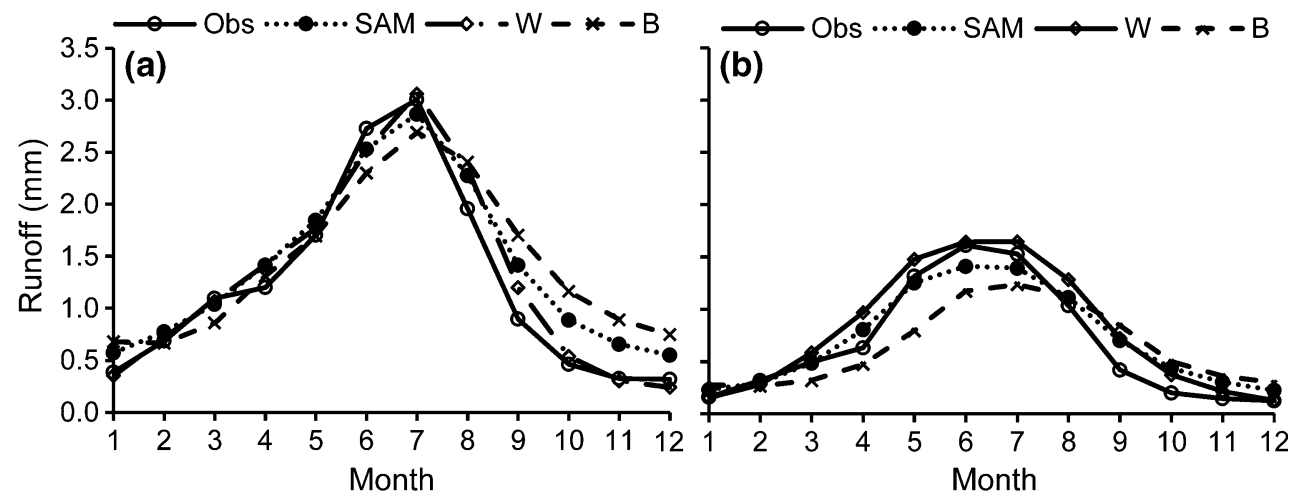

Based on the three considered methods for simulating the anthropogenic interventions and climate change impacts on streamflow from 1998 to 2013, climate change was the leading factor for the decline (66 to 97\%) of streamflow. Climate change was the main factor reducing runoff for the periods 1998-2002, 2003-2008 and 2008-2013. Anthropogenic intervention impacts such as land use and cover changes, water conservancy project implications, and soil conservation actions might accumulate or counteract each other simultaneously, and further research on these challenges is recommended. Furthermore, research findings imply that river alteration, climate variability and anthropogenic interventions should be considered for future stream basin managing strategies to avoid the temporal mismatch between strategies and such changes.

The simulation outcomes reveal that there is a big variance in the performance of the considered hydrological models in simulating the runoff. Simply averaging the single model simulation would result in consensus multimodel simulations that are superior to any individual simulations which confirmed that the SAM multi-model combination technique is applicable tool to extract the strengths from different models whereas avoiding the weaknesses. More sophisticated multi-model combination approaches can improve the simulation accuracy. This suggests that further operational hydrologic simulations should incorporate a multi-model combination strategy. The multi-model simulation accuracy is associated with that of the single models. On the one hand, if single model simulation accuracy is poor in matching measurements, removing that model from simulation does impact the accuracy of multi-model simulations very much. On the other hand, excluding the best performing model from consideration does negatively impact the accuracy of multi-model simulation.

The current research is based on the hydrological simulation of only three models and a total of 35 years of daily runoff data. More models and larger datasets can enhance the multi-model combination outcomes, but this needs to be explored further. Model combination techniques are still new in hydrology. However, initial findings indicate that they might be a preferable alternative to individual model simulation. This study represents a critical step toward better understanding of the potential effect of climate variability, anthropogenic interventions and subsequent drought events on streamflow in the LZRB and similar other regions with arid and semi-arid climate. The research outcomes will benefit engineers and policy-makers in assessing water resources at a basin scale.

Acknowledgements The research presented has been financially supported by the Iraqi Government. Thanks go to Amjad Hussain (The University of Salford) for his kind help and support.

Open Access This article is distributed under the terms of the Creative Commons Attribution 4.0 International License (http://crea tivecommons.org/licenses/by/4.0/), which permits unrestricted use, distribution, and reproduction in any medium, provided you give appropriate credit to the original author(s) and the source, provide a link to the Creative Commons license, and indicate if changes were made.

\section{References}

Ajami NK, Duan Q, Gao X, Sorooshian S (2006) Multi-model combination techniques for hydrological forecasting: application to distributed model intercomparison project results. J Hydrometeorol 7(4):755-768. doi:10.1175/JHM519.1

Ajami NK, Duan QY, Sorooshian S (2007) An integrated hydrologic Bayesian multi-model combination framework: confronting input, parameter, and model structural uncertainty in hydrologic prediction. Water Resour Res 43:W01403

Aksoy H, Gedikli A, Unal NE, Yilmaz M, Eris E, Yoon J, Tayfur G (2016) Rainfall-runoff model considering microtopography simulated in a laboratory erosion flume. Water Res Manag. doi:10.1007/s11269-016-1439-y

Al-Ansari NA (2013) Management of water resources in Iraq: perspectives and prognoses. Engineering 5:667-684. doi:10. 4236/eng.2013.58080

Al-Ansari NA, Ali AA, Knutsson S (2014) Present conditions and future challenges of water resources problems in Iraq. J Water Res Prot 6(12):1066-1098. doi:10.4236/jwarp.2014.612102

Allen RG, Pereira LS, Raes D, Smith M (1998) Crop evapotranspiration: guidelines for computing crop water requirements. Food 
and Agriculture Organization (FAO) Irrigation and Drainage Paper 56, first ed, Rome

Bozkurt D, Sen OL (2012) Climate change impacts in the EuphratesTigris Basin based on different model and scenario simulations. J Hydrol 480:149-161. doi:10.1016/j.jhydrol.2012.12.021

Bozkurt D, Sen OL, Hagemann S (2015) Projected river discharge in the Euphrates-Tigris Basin from a hydrological discharge model forced with RCM and GCM outputs. Clim Res 62(2):131-147. doi: $10.3354 / \mathrm{cr} 01268$

Chang J, Wang YM, Istanbulluoglu E, Bai T, Hunang Q, Yang D, Huang S (2015) Impact of climate change and human activities on runoff in the Weihe river basin, China. Quat Int 380-381:169-179

Chen YN, Xu ZX (2005) Plausible impact of global climate change on water resources in the Tarim River Basin. Sci China Ser D (Earth Sci) 48(1):65-73

Cheng Y, He H, Cheng N, He W (2016) The effects of climate and anthropogenic activity on hydrologic features in Yanhe River. Adv Meteorol. doi:10.1155/2016/5297158

Cullen HM, deMenocal PB (2000) North Atlantic influence on Tigris-Euphrates streamflow. Int J Climatol 20:853-863

Dahamsheh A, Aksoy H (2007) Structural characteristics of annual precipitation data in Jordan. Theor Appl Climatol 88(3):201-212. doi:10.1007/s00704-006-0247-3

Devi GK, Ganasri BP, Dwarakish GS (2015) A review on hydrological models. international conference on water resources, coastal and ocean engineering (ICWRCOE'15). Aquat Proc 4:1001-1007. doi:10.1016/j.aqpro.2015.02.126

Duan QY, Ajami NK, Gao XG, Sorooshian S (2007) Multi-model ensemble hydrologic prediction using Bayesian model averaging. Adv Water Res 30:1371-1386. doi:10.1016/j.advwatres. 2006.11.014

Fadhil MA (2010) Drought mapping using geoinformation technology for some sites in the Iraqi Kurdistan region. Int J Digit Earth 4(3):239-257

FAO (2012) Adaptation to climate change in semi-arid environments. Experience and lessons from Mozambique. Environment and Natural Resources Management Series. Food and Agriculture Organization (FAO) of the United Nations, Rome, pp. 1-83. http://www.fao.org/docrep/015/i2581e/i2581e00.pdf. Accessed 19 July 2016

Futter MN, Whitehead PG, Sarkar BS, Roddad CH, Crossman J (2015) Rainfall runoff modelling of the Upper Ganga and Brahmaputra basins using PERSiST. Environ Sci Process Impacts. doi:10.1039/c4em00613e

Georgakakos KP, Seo DJ, Gupta H, Schake J, Butts MB (2004) Characterizing streamflow simulation uncertainty through multimodel ensembles. J Hydrol 298:222-241. doi:10.1016/j.jhy drol.2004.03.037

Guo Y, Li Z, Amo-Boateng M, Deng P, Huang P (2014) Quantitative assessment of the impact of climate variability and human activities on runoff changes for the upper reaches of Weihe River. Stoch Environ Res Risk Assess 28(2):333-346

Huang SZ, Liu DF, Huang Q, Chen Y (2016) Contribution of climate variability and human activities to the variation in runoff in Wei River Basin, China. Hydrol Sci J 61(6):1026-1039

Huo Z, Feng S, Kang S, Li W, Chen S (2008) Effect of climate changes and water-related human activities on annual stream flows of the Shiyang river basin in arid north-west China. Hydrol Process 22:3155-31167

Jiang S, Ren L, Yong B, Singh VP, Yang X, Yuan F (2011) Quantifying the effects of climate variability and human activities on runoff from the Laohahe basin in northern China using three different methods. Hydrol Process 25:2492-2505

Jiang S, Ren L, Yang X, Ma M, Liu Y (2014) Mulit-model ensemble hydrologic prediction analysis. In: Evolving water resources systems: understanding, predicting and managing water-society interaction proceedings of ICWRS 2014, Bologna, Italy, June 2014 (IAHS Publ 364, 2014)

Jiang C, Xiong L, Wang D, Liu P, Guo S, Xu C-Y (2015) Separating the impacts of climate change and human activities on runoff using the Budyko-type equations with time-varying parameters. J Hydrol 522:326-338

Jones RN, Chiew FHS, Boughtom WC, Zhang L (2004) Estimating the sensitivity of mean annual runoff to climate change using selected hydrological models. Adv Water Res 29:1419-1429

Kahya E, Kalayci S (2004) Trend analysis of streamflow in Turkey. J Hydrol 289:128-144

Li LJ, Zhang L, Wang H, Wang J, Yang JW, Jiang DJ, Li JY, Qin DY (2007) Assessing the impact of climate change and human activities on streamflow from the Wuding River basin in China. Hydrol Process 21:3485-3491

Ma ZM, Kang SZ, Zhang L, Tong L, Su XL (2008) Analysis of impacts of climate change and human activity on streamflow for a river basin in arid region of northwest China. J Hydrol 352:239-349

Mao Y, Nijssen B, Lettenmaier DP (2015) Is climate change implicated in the 2013-2014 California drought? A hydrologic perspective. Geophys Res Lett 42(8):2805-2813

Miao C, Ni J, Borthwick AGL, Yang L (2011) A preliminary estimate of human and natural contributions to the changes in water discharge and sediment load in the Yellow River. Glob Planet Change 76:196-205

Perrin C, Michel C, Andréassian V (2003) Improvement of a parsimonious model for streamflow simulation. J Hydrol 279:275-289

Robaa SM, AL-Barazanji ZJ (2013) Trends of annual mean surface air temperature over Iraq. Nat Sci 11(12):138-145

Saeedrashed Y, Guven A (2013) Estimation of geomorphological parameters of lower Zab River-Basin by using GIS-based remotely sensed image. Water Res Manag 27(1):209. doi:10. $1007 / \mathrm{s} 11269012-0179-\mathrm{x}$

Seibert J, Vis M (2012) Teaching hydrological modeling with a user-friendly catchment-runoff-model software package. Hydrol Earth Syst Sci 16:3315-3325. doi:10.5194/hess-163315-201

Sen OL, Unal A, Bozkurt D, Kindap T (2012) Temporal changes in the Euphrates and Tigris discharges and teleconnections. Environ Res Lett 6(2):1-9. doi:10.1088/1748-9326/6/2/024012

Tabari H, Taalaee PH (2011) Analysis of trend in temperature data in arid and semi-arid regions of Iran. Glob Planet Change 72:1-10

Tigkas D, Tsakiris G (2004) Medbasin: a Mediterranean rainfallrunoff software package. Eur Water 5(6):3-11

Tigkas D, Vangelis H, Tsakiris G (2012) Drought and climatic change impact on streamflow in small watersheds. Sci Total Environ 440:33-41

Tsakiris G, Loukas A, Pangalou D, Vangelis H, Tigkas D, Rossi G, Cancelliere A (2007) Drought characterization [Part 1. Components of drought planning. 1. 3. Methodological component]. In: Iglesias A, Moneo M, López-Fran cos A (eds) Drought management guidelines technical annex CIHEAM/ECMEDA Water, Zaragoza, pp 85-102 (Options Méditerranéennes: Série B. Etudes et Recherches; n. 58)

UN-ESCWA and BGR Inventory of Shared Water Resources in Western Asia (2013) United Nations Economic and Social Commission for Western Asia (UN-ESCWA) and Bundesanstalt für Geowissenschaften und Rohstoffe (BGR), Beirut

Vaheddoost B, Aksoy H (2016) Structural characteristics of annual precipitation in Lake Urmia basin. Theor Appl Climatol. doi:10. 1007/s00704-016-1748-3

Vallam P, Qin XS, Yu JJ (2014) Uncertainty quantification of hydrologic model. APCBEE Procedia 10:219-223 
Velázquez JA, Anctil F, Ramos MH, Perrin C (2011) Can a multimodel approach improve hydrological ensemble forecasting? A study on 29 French catchments using 16 hydrological model structures. Adv Geosci 29:33-42. doi:10.5194/adgeo-29-33-2011

Wang W, Shao Q, Yang T, Peng S, Xing W, Sun F, Luo Y (2012) Quantitative assessment of the impact of climate variability and human activities on runoff changes: a case study in four catchments of the Haihe River basin, China. Hydrol Process. doi:10.1002/hyp.9299

Ye X, Zhang Q, Liu J, Li X, Xu CY (2013) Distinguishing the relative impacts of climate change and human activities on variation of streamflow in the Poyang Lake catchment, China. J Hydrol 494:83-95
Zhang L, Dawes WR, Walker GR (2001) Response of mean annual evapotranspiration to vegetation changes at catchment scale. Water Resour Res 37(3):701-708

Zhao F, Zhang L, Xu ZX, David FS (2010) Evaluation of methods for estimating the effects of vegetation change and climate change on streamflow. Water Resour Res 46:W03505

Zheng Z, Wen-Xi LU, Hai-Bo C, Wei-Guo C, Ying Z (2014) Uncertainty analysis of hydrological model parameters based on the bootstrap method: a case study of the SWAT model applied to the Dongliao River Watershed, Jilin Province, Northeastern China. Sci China Technol Sci 57(1):219-229 